\title{
US scientists fight political meddling
}

\section{ST LOUIS, MISSOURI}

The rift between US scientists and the administration of President George W. Bush widened last weekend, as Nobel-prizewinning biologist David Baltimore used the annual meeting of the American Association for the Advancement of Science (AAAS) in St Louis to denounce government suppression of scientific findings.

Speaking last Saturday to a packed conference room, Baltimore - the president-elect of the AAAS - urged scientists to challenge perceived censorship of their research. Tensions between the Bush administration and researchers have been high for years, but Baltimore said he had recently grown convinced that the problem cannot be shrugged off as the usual battles between science and politics.

"It is no accident that we are seeing such extensive suppression of science," he said. "It is part of a theory of government, and I believe it is a theory that we must vociferously oppose." In particular, Baltimore condemned the "unitary executive" theory of government - the notion that a president can bypass Congressional and judicial oversight and run the country single-handedly (see page 891). Baltimore argued that this approach threatens to undermine the independence of science conducted under the auspices of the federal government.

Major US science agencies such as NASA, the National Science Foundation and the National Institutes of Health are all part of the

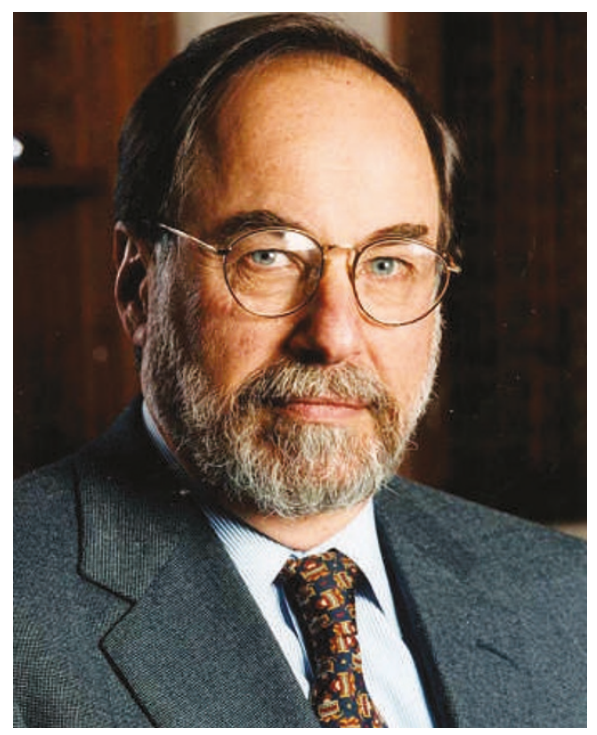

David Baltimore has called for opposition to the Bush administration's "suppression of science".

executive branch of government, meaning that their employees answer ultimately to the president. In recent weeks, several researchers have gone public with charges that their government minders censored or otherwise manipulated their findings (see 'Censored Science?').

The latest round began last month, when James Hansen, a climate scientist at NASA's Goddard Institute for Space Studies in New
York, charged that NASA was trying to stop him doing media interviews that might cover policies on greenhouse-gas emissions. The 24year-old NASA press officer who was the source of many of Hansen's complaints eventually resigned (see Nature 439, 643; 2006).

The accusations have left many government-funded researchers wondering about their role in public debate over science policy. Are they allowed to speak their mind based on the latest science? Or must they hold their tongue and respect their employer's wishes?

"There's no precise line that has been laid down," says Daniel Greenberg, a guest scholar at the Brookings Institution, a non-partisan think-tank based in Washington DC. Instead, scientists must navigate the grey zone where science meets public policy.

Scientists employed by the government have different rights from those at universities or other private institutions, says Louis Clark, president of the Government Accountability Project, a Washington-based non-profit that is advising Hansen. Federal scientists, he says, can present their data publicly but must be clear that they are not representing their agency or government policy. "The cardinal rule," Clark says, "is that you can speak for yourself, but you can't speak for the government unless you're authorized to do so." Australia's largest funding agency, where scientists are also claiming to have been blocked from

\section{Culture of fear reigns at Australian research lab}

\section{SYDNEY}

Claims from Australian scientists that they have been gagged in discussions of climate change have revealed a culture of fear at the nation's leading research laboratory.

An investigative television programme aired by the Australian Broadcasting Corporation on 13 February claimed that three prominent climate scientists from the Commonwealth Scientific and Industrial Research Organisation (CSIRO) were censored in discussions of climate change and energy research.

Against the backdrop of the Australian government's refusal to back the Kyoto Protocol on climate change, there has been a public outcry over this and other media reports of political interference in the prominent research agency, which publishes high-impact studies on climate change. Political opponents have called for an independent inquiry into the allegations. On 21 February, the CSIRO announced a review of how it provides scientific input into policy development.

Graeme Pearman, a CSIRO veteran and former chief of the agency's atmospheric research division, says that in 2004 he was advised to withdraw his name from a report by the independent

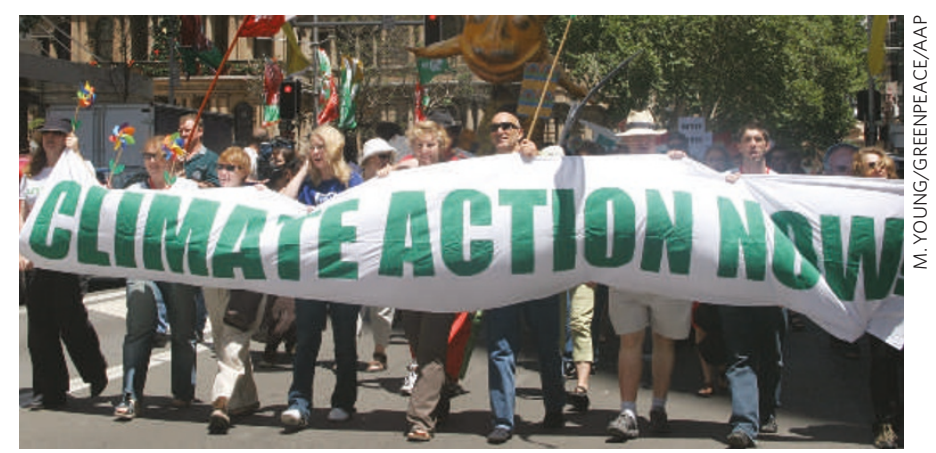

In the streets: Sydneyites protest at Australia's refusal to ratify Kyoto.

Australian Climate Group that recommended targets for reducing greenhouse-gas emissions.

Steve Morton, chief of CSIRO

Sustainable Ecosystems, and
Pearman's manager at the time, admits that he asked Pearman not to participate but denies that scientists are censored. "We encourage our scientific staff to 


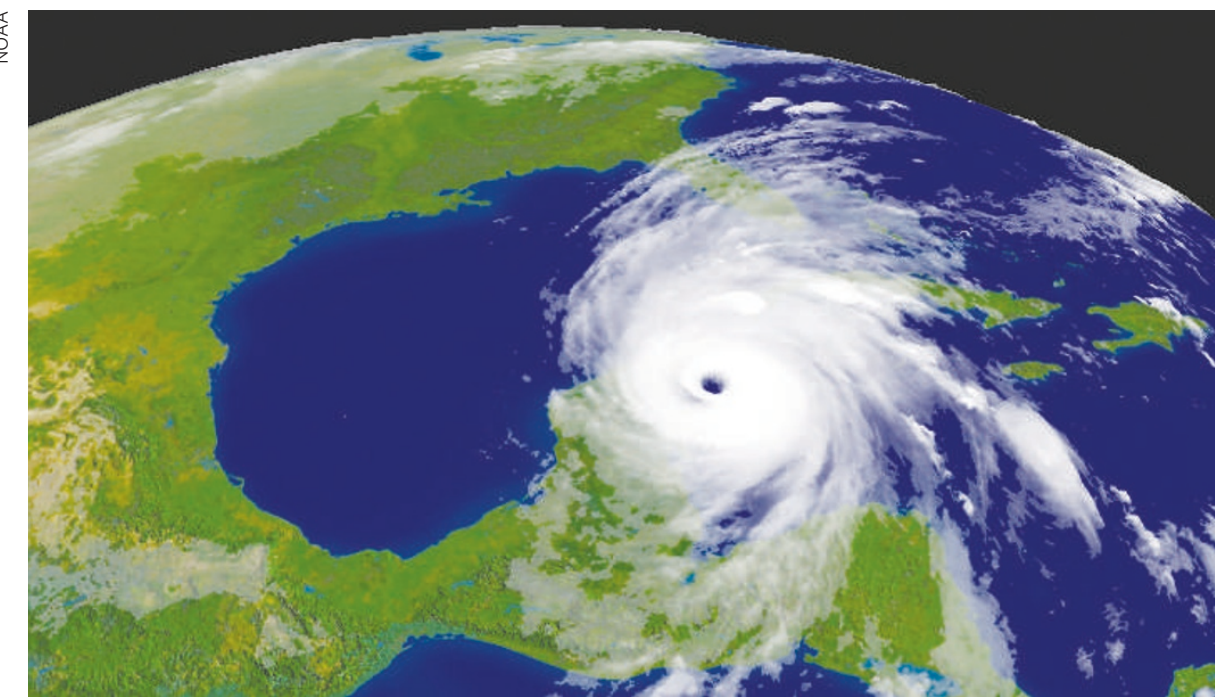

Hot topic: researchers have attacked official denials that hurricanes are linked to climate change.

talking about climate and energy research, makes a similar argument (see below).

Still, Hansen and others say that they must speak their minds for science to proceed. Hansen, for instance, is an expert on global temperature records, which are relevant to policies on greenhouse gases. "How can a democracy function," he asks, "if the public is not informed, honestly and fully informed?"

Such tales are not unique to the Bush administration. In 1993, physicist William Happer resigned unwillingly as head of the Department of Energy's Office of Energy Research after contradicting then-vice-president $\mathrm{Al}$ Gore. The vice-president had stated that ozone depletion at the South Pole would lead to dangerous amounts of ultraviolet- $\mathrm{B}$ radiation; Happer pointed out that the oblique angle at which the sun hit the pole meant that even a thin ozone layer could absorb the rays.

But the current administration's policies on climate change, which most scientists agree are far out of step with the best available data, have exacerbated the situation.

Not all government employees have felt pressured. Rita Colwell, who headed the National Science Foundation under presidents Clinton and Bush, told the AAAS meeting that she had "not at any time come under political pressure from any quarter".
BIRD FLU HERE TO STAY?

Experts warn that $\mathrm{H} 5 \mathrm{~N} 1$

could become entrenched

in Europe.

www.nature.com/news

\section{CENSORED SCIENCE?}

Public-affairs officers are at the sharp end of charges that science is being suppressed or watered down by US government officials. Among the recent accusations:

- In October 2004, a NASA press officer was reportedly pressured by her boss to delay a news conference on ozone and air pollution until after the presidential election the following month.

- A University of Colorado sea-ice expert argues that NASA last autumn watered down a university press release to remove mention of accelerating sea-ice decline. NASA is re-evaluating its media policies.

Scientists at the National Oceanic and Atmospheric Administration have protested at the agency's public position that denies any links between hurricanes and global warming. The administration recently updated its website to acknowledge that some researchers see a connection.

But speaking after Colwell, Susan Wood, a former scientist at the Food and Drug Administration, spoke of her reasons for resigning last August, after her boss repeatedly delayed a decision to make the Plan B contraceptive more widely available (see Nature 437, 179; 2005). The morale of scientists at her former agency was at its lowest point ever, Wood said. She got a standing ovation.

Colin Macilwain and Geoff Brumfiel speak about their work. But there are certain areas where we urge them to tread warily and not to beat someone else's political drum."

Like US science agencies (see above), the CSIRO's official policy permits staff to discuss their scientific work, but advises against commenting on government policies. It says they should only express private opinions when it is clear that it is their personal view. But the line between science and policy is blurred, say CSIRO scientists, with the greatest tension being in environmental research into climate, water and energy.

"Scientists are encouraged to do policy-relevant research and yet not be policy prescriptive - there is a very fine line," says climate expert Barrie Pittock, another CSIRO veteran who spoke out in the television programme. Pittock says he was told not to discuss mitigation in a 2003 report commissioned by the government's Australian Greenhouse Office. In particular, he says he was asked to tone down his discussion of how rising sea levels could displace people in southeast

Asia, because of potential immigration implications for Australia.

Critics say the CSIRO's weakness in public debates on environmental issues in the face of conservative government policies is down to financial insecurity. Government funding has been eroded and there is pressure on the agency to find external funding sources and industry partners. "There are a lot of fearful science managers second-guessing what they think government wants to hear," says the third whistleblower, Barney Foran, who retired from the CSIRO last year. When the government appointed a biofuel

taskforce in 2005, Foran says, he was warned not to say anything negative about ethanol fuel.

Other ex-CSIRO scientists deny being censored, but acknowledge that the mood at the agency has changed in recent years. "The CSIRO is very mute on key environmental issues at the moment," says John Williams, who retired from the CSIRO in 2004 after heading the land and water division. And there is concern that younger staff feel constrained. "Anyone who has a baby and a mortgage would be crazy to speak out," says Foran.

But the culture of fear has been created by perception rather than reality, says Michael Borgas, president of the CSIRO's staff association. "The crux of the problem is job insecurity," he says, pointing out that annual staff turnover is $21 \%$ and that most new positions are short-term or casual appointments. "With that backdrop, people aren't going to be pushing issues or debates that bring the spotlight on them."

Carina Dennis 